\title{
Environmental Education in China: \\ Development, Difficulties and Recommendations
}

\author{
Youyi Tian (Corresponding author) \\ School of Education, Central China Normal University \\ 152 Luoyu Road, Wuhan, Hubei Province 430079, P. R. China \\ Tel: 86-134-7612-7439Ｅ-mail: youyitian@mail.ccnu.edu.cn \\ Chenyu Wang \\ Curry School of Education, University of Virginia \\ 405 Emmet Street, Charlottesville, VA 22904, United States \\ Tel: 1-301-538-8020 E-mail: cw6bc@virginia.edu
}

Received: February 21, 2015 Accepted: August 3, 2015 Published: August 12, 2015

doi:10.5296/jsss.v3i1.7144 URL: http://dx.doi.org/10.5296/jsss.v3i1.7144

\begin{abstract}
With China's economic take off since the 1990s, environmental degradation, such as climate change, energy crises, and conflicts from environmental devastation become more and more serious. As such, environmental education (EE), which has been implemented since 1973, shoulders a pivotal role in maintaining the balance between economic growth and environmental sustainability. This paper reviews EE's development in China and, examines the characteristics and conceptual difficulties of EE, including the unscientific understanding on EE, low-level of motivation to incorporate EE in teachings, the lack of environmental awareness, and contradiction between economic growth and environmental protection and sustainable development. Recommendations to EE include: (1) the fundamental framework of EE should gear toward providing adequate awareness, knowledge, attitude, skills, evaluation ability, and participation for EE and education for sustainable development (ESD) in China; (2) policies of EE need to be enacted and implemented, so as to reflect the diverse needs based on developing economic growth and cultural situations across the country; (3) it is imperative to accelerate the legislation process of environmental education law; and (4) government, regions, and environmental non-government organizations (NGOs) should foster
\end{abstract}


and strengthen its bilateral or multilateral international exchanges and cooperation.

Keywords: Environmental education, Sustainable development, Environmental sustainability, Education for sustainable development, China

\section{Introduction: Global Context for the Development of Environmental Education}

With the implementation of Reform and Opening-up Policy since 1978, China has registered highly visible economic growth, which in turn resulted in serious environmental problems. China is facing huge challenges such as environmental protection, resource conservation, climate change adaptation and mitigation. Therefore, it is very important for China to seek a way to keep a balance between economic growth and environmental sustainability.

As a result, following the trend of environmental education (EE) on the globe, China has implemented and promoted EE since 1973, after the 1972 United Nations Conference on the Human Environment, also known as Stockholm conference. As the conference promulgated the Stockholm Declaration on the Human Environment, EE was included in Principal 19.

Education in environmental matters, for the younger generation as well as adults, giving due consideration to the underprivileged, is essential in order to broaden the basis for an enlightened opinion and responsible conduct by individuals, enterprises and communities in protecting and improving the environment in its full human dimension. ...(Sohn, 1973).

In 1977, the World's First International Conference on Environmental Education, organized by United Nations Educational, Scientific and Cultural Organization (UNESCO) in cooperation with the United Nations Environment Program (UNEP) was convened in Tbilisi, Georgian, USSR. Tbilisi Declaration explicitly defined the roles, objectives, and characteristics of EE. The Declaration and also recommendations of the conference set a guideline for the framework, principles and guidelines for $\mathrm{EE}$ at local, national, regional and international levels for all age groups both inside and outside the formal school system (UNESCO-UNEP, 1978).

Another important concept that constitutes EE is sustainable development (SD). It was first discussed at the 1992 Rio de Janeiro United Nations Conference on Environment \& Development (UNCED). In Chapter 36 of Agenda 21, "Promoting Education, Public Awareness and Training", it pointed out that,

Education is critical for promoting sustainable development and improving the capacity of the people to address environment and development issues. ... It is also critical for achieving environmental and ethical awareness, values and attitudes, skills and behavior consistent with sustainable development and for effective public participation in decision-making (UN DESA, 1992, Agenda 21-36.3).

The connection between education and SD became explicit on the 1994 National Forum on Partnerships Supporting Education about the Environment. During the forum, policy makers issued a document entitled "Education for Sustainability: An Agenda for Action", which laid out a number of recommendations as to how we can build concepts of sustainability into our 
educational programs. The concept "Education for Sustainability" (EfS) was then put forward. EfS recognized that "human rights and social justice are just as essential to sustainable development as environmental sustainability" (Gough, 2005).

In 1997, the International Conference on Environment and Society: Education and Public Awareness for Sustainability was organized in Thessaloniki by UNESCO and the Government of Greece, and the Declaration of Thessaloniki was issued. The Declaration reaffirmed:

Environmental education, as developed within the framework of the Tbilisi recommendations and as it has evolved since then, addressing the entire range of global issues included in Agenda 21 and the major UN Conferences, has also been dealt with as education for sustainability. This allows that it may also be referred to as education for environment and sustainability (UNESCO-EPD, 1997).

The Declaration argued that the concept of environmental sustainability must be clearly linked with poverty, population, health, food security, democracy, human rights and peace, and a respect for cultural diversity and traditional knowledge. Thus EE began to be expanded to education for sustainable development (ESD).

As EE and ESD began to engage global and local education polices, the concepts and concerns of SD have been applied to or integrated with EE of China since the 1992 Rio de Janeiro United Nations Conference.

\section{The Development of EE in China}

Not only did the Reform and Opening-up Policy bring unprecedented economic growth to China, but also huge scale of environmental deconstruction and degradation. Under the influence of the Motto that "Development is the hard truth," the contradiction between economic growth and environmental sustainability is a major challenge for China. In the late 1970s, China began to take measures for environmental protection, and started to consider EE. The development of EE also originated from the late 1970s, and was divided into four phases. The section below gives a brief chronological review of the development of EE in China.

\subsection{Phase I (1973-1983): The Preliminary Stage of EE}

The first phase of EE in China lasted from 1973 through 1983, during which period environmental protection was a new concept. In this preliminary phase of EE, the emphasis was on the knowledge of environmental protection technologies (Tian, 2008). Towards this end, higher educational institutions establish academic programs on EE, and legal documents were drafted and implemented as well.

Held in 1973, the first National Meeting on Environmental Protection called for efforts to conduct research, communication, and education on environmental protection for the first time. The conference resulted in a document, Provisions on Environment Protection and Improvement, which require Chinese colleges and universities to set up academic disciplines and curricula on environmental protection. This conference marks the beginning of environmental protection and EE in China, and also set the basic framework of EE in China 
(Huang, 2003).

Hence, higher educational institutions in China began to offer courses and majors about environment protection. For instance, Tsinghua University founded environmental engineering as a major in 1977. Beijing Normal University also began to offer graduate programs on environmental protection through the Department of Geography in 1978. In 1979, the First Meeting of the Education Working Committee of Chinese Society for Environmental Sciences (CSES) decided to conduct experimental EE programs at selected primary and secondary schools. In 1981, the Second Meeting of the Education Working Committee of CSES recommended the establishment of a comprehensive environmental education system from basic education through higher education (CSES, 2008). These meetings promoted to launch $\mathrm{EE}$ in the education system, and teachers in primary and secondary schools began to be aware of the importance of EE.

During this phase, the Environmental Protection Law of the People's Republic of China (PRC) (for Trial Implementation) was enacted in 1979, which ensured the development of EE. A number of magazines, such as Environmental Protection (1973), Environment (1978), World Environment (1983), began to be published. Meanwhile, China Environmental Science Press was established in 1980. These magazines and press undertook the important tasks of promoting the information, knowledge, policies, and laws, which represented the establishment of the communication system of EE in China.

\subsection{Phase II (1983-1992): The Formation and Developmental Stage of EE}

The second phase from 1983 to 1992 was the period of formation and development of EE. During this phase, environmental protection was being institutionalized, and the emphasis was laid on improving the environmental awareness of government officials and the public. Specifically, environmental protection was recognized as a fundamental national policy during the Second National Meeting on Environmental Protection held in 1983. Since this meeting, EE in China began to enter the formation and developmental stage (Cui, 2009).

In 1985, the National Conference of Experience Exchange and Academic Seminar on EE in Primary and Secondary Schools started to cooperate with a common effort between education departments and environmental protection departments, for the first time put forward the idea of permeating EE in each subject of elementary and secondary schools (CSES, 2008). The conference laid the foundation for the development of EE in primary and secondary schools throughout the country.

Since then, EE was required to be integrated into the curricula in basic education in official documents. These include Teaching Program in Full Time Ordinary Primary School and Junior High School for 9-Year Compulsory Education (for Trial Implementation) (1987), Suggestion to the Adjustment of the Current Curriculum in High School (1990), Curriculum Plan in Full time Ordinary Primary School and Junior High School for 9-Year Compulsory Education (for Trial) (1992). In the Suggestion to the Adjustment of the Current Curriculum in High Schools (1990), it also required high schools to offer elective courses on environmental protection (Tian, 2001). 
Furthermore, through different media venues, the concept of environmental protection was further disseminated to the public. The first environmental newspaper, China Environment Daily, began to publish in 1984; the National Environmental Protection Agency (NEPA) was set up, then became the Bureau of Environmental Protection within Ministry of Town and Country Construction (now Ministry of Construction of China) in 1988 for strengthening macro guidance of EE; and the Environmental Protection Law of PRC was enacted in December 1989 (Amended in 2014), in which established the legal status of EE with an important role in environmental protection.

\subsection{Phase III (1992-2002): Sublimation of EE for SD}

Building on the second stage, Phase III of EE in China marks the reorientation of EE to SD. Moreover, ESD replaced EE and became more prevalent in China.

In response to the Rio de Janeiro United Nations Conference, China promulgated Ten Countermeasures to Environment and Development (1992) in which the implementation of SD and improvement of the whole nation's environmental awareness through strengthening EE were two of the ten countermeasures. It was China's first time to link "environment" with "development," indicating the beginning of reorientation of EE to ESD. During the same year, the First National Meeting for EE was held, requiring EE to serve as a basic way to solve environmental problems (Yen, 1993).

China's Agenda 21, the White Paper on Population, Environment and Development of China in the 21st Century, was released in 1994. The White Paper emphasizes on the idea of SD from primary education through higher education; it also seeks to heighten the public's awareness of SD (Cheng, \& Sun, 2009). It marks the beginning of the establishment and implementation of SD as a national strategy. The core of EE in China was then reoriented towards to ESD. Furthermore, the National Action Guidelines for Environmental Communication and Education (1996-2010) was promulgated in 1996. The Guidelines stipulated that by the year 2000 "Green School Program" would be promoted throughout the country and schools meeting general criteria for a "green" curriculum, administration, way of living and environment would receive green school certification.

Civil societies on EE were also established in China during this stage. Since the mid-1990s, a number of environmental non-government organizations (NGOs) emerged, such as China's first environmental NGO, Friends of Nature (FON). NGOs spread information about the importance of environmental protection and SD (Lin, \& Ross, 2005). In terms of academic research, the journal of Environmental Education was launched in 1995, which publishes theoretical papers on EE, environmental policies, successful EE programs, activities and experiences, etc.

\subsection{Phase IV (2002-): Reorientation of EE to ESD}

The fourth phase began in 2002, and EE is practically being immersed with ESD. In this phase, EE has been developing all over the country, at all levels and with all forms in implementation. ESD began entering the documents, and ESD activities quickly spread across the country. 
In 2003, the Chinese government declared the Notion of Scientific Development (NSD), which illuminated the Chinese understanding of SD. In brief, NSD envisions the construction of an ecological civilization (Yu, 2005). Therefore, NSD orients EE for an ecological civilization and new lifestyles. In order to implement the NSD, MoE issued two documents in 2003, a Special Curriculum for Environmental Education in Primary and Secondary Schools, and an Implementation Guidelines on Environmental Education for Primary and Secondary Schools. These two documents require that environmental knowledge, attitudes, and values be integrated into the compulsory school curriculum. For example, the Special Curriculum directed all bureaus of education and schools, starting in the spring of 2003, to: (1) offer courses on EE as an independent subject, (2) fully integrate EE into school schedules, (3) offer teacher training, and (4) conduct research on EE pedagogies. These two policy documents officially stipulated the formal integration of EE to primary and secondary school. Since then, ESD is supposed to become an integral component in basic education reform in China.

The Symposium on Ecological Civilization and Harmonious Society was held at Jiufeng National Forest Park in Beijing in 2007, and the Jiufeng Declaration was issued, in which strengthening education for an ecological civilization was stressed. The 2008 Beijing Olympic Games advocated and actively fulfilled the pledge of a Green Olympics, which was seen as an important way to promote education for ecological civilization.

In 2011, The National Action Guidelines for Environmental Communication and Education (2011-2015) was promulgated, requiring the establishment of an implementation system of environmental protection, to strengthen environmental communication and education, to enhance the people's awareness of environmental protection. The goal of cultivating an ecological civilization is to be fostered.

\subsection{Discussion}

The development of EE in China shows a top-down government-led model, which is mainly embedded in the following aspects: (1) the main purposes of EE are to acquire environmental science knowledge and form environmental awareness; (2) government organizations, especially the environmental protection departments absolutely hold the dominant position; (3) the forms of EE include environmental communication and environmental education; (4) the objects of EE are to influence all citizens, especially the government officials and professional and experts; (5) the content of EE puts emphasis on environmental knowledge and monitoring, and treatment skills of environmental pollution; and (6) EE pays more attention to professional education, whereas non-professional education is relatively ignored.

\section{EE in China: Some Initial Reflections}

Compared with international EE, EE in China started relatively late. Since 1973, EE in China has made considerable development, and gradually formed a multi-form, multi-level, and multi-channel EE system. The historical development of EE in China can be divided into four different stages: the preliminary stage of EE, the formation and developmental stage of EE, sublimation of EE for SD, and reorientation of EE to ESD. During the course, EE in China 
moves from "education for environment" to "ESD", and then to "education for an ecological civilization."

In the following, we will examine some important features of EE in China based on a reflection on the four stages outlined above.

\subsection{Emphasis on Awareness in EE in China}

In reviewing the history of EE's development in China, one finds that the basic conceptualization of EE derives from the Stockholm conference in 1972. The Conference argued that environmental problems were mainly due to people's ignorance and unconcern (Sohn, 1973). Therefore, battling the ignorance and unconcern becomes the primary means through which environment problems can be solved. Such an attitude directly influenced Chinese EE's emphasis on knowledge and awareness about environmental protection. Ways in which EE is conceptualized, systemized, and implemented derive from this basic approach on environmental protection.

This can go directly back to the 1970s, when the government aimed at exposing pollution and ecological degradation. By then, the general public was not aware of the importance of environmental protection. Some even argued against actions for environmental protection. Under such circumstances, environmental protection became a difficult task. Therefore, awareness of the seriousness of environmental issues became the primary task of fostering environmental protection in China, and the Chinese citizens were led to understand EE as a primary means of spreading environmental science.

During major conferences on the development of EE in China, including the National Meeting on Environmental Protection, the Meeting of the Education Committee of CSES, the National Meeting for EE, conference participants placed utmost importance on the awareness on EE. Hence, EE becomes a discipline that imparts factual knowledge. To some extent, this leads to the more significant on knowledge acquisition and environmental protection awareness in EE in China.

\subsection{Two Basic Themes of EE in China}

Governmental officials play an important role in China. If they did not raise their awareness about EE, few changes can be implemented. As such, governmental officials are one of the primary audience of China's EE. During the Third National Conference on Environmental Protection, it was stressed the communication and education of environmental protection should be strengthened, and the environmental awareness at all levels of governmental officials should be improved. Similarly, Mr. Geping Qu, the then director of NEPA, highlighted EE's emphasis as the training of governmental officials at all levels.

A second theme of $\mathrm{EE}$ is its emphasis on cultivating professionals and experts on environmental protection. Due to the government's approach on environment management, which can be described as "no overall plan for a fundamental transformation," China were in dire need of experts specializing in related environmental disciplines and fields. Therefore, educating professionals on environmental protection become one of the major approaches on 
environmental protection in China. The policy document of the First National Conference on Environmental Protection stipulates that higher educational institutions should set up majors and courses about environment protection, and cultivate professionals and experts. As a result, a few universities and colleges, such as Peking University, have founded majors on this front. In subsequent conferences and policy documents, such as the National Meeting on Environmental Protection, the National Meeting for EE, the State Council promulgated Decisions on Enhancing Environmental Protection During Economic Adjustment Period, the Environmental Protection Law of PRC, cultivating professionals on EE has been referenced multiple times. This has led to the gradual and then comprehensive offering of environmental science majors throughout colleges and universities in China.

\subsection{Two Modes of EE in China}

There are primarily two modes of EE in China. The first one relates to publicizing and raising awareness of environment issues to the general public. Specifically, this has taken the form of media publication, including newspapers, TV and radio broadcasting, etc. The second one takes the form of formal EE at schools. Two models can be further differentiated under this category: general EE and professional EE. General EE mainly includes classes taught for the purpose of imparting knowledge on the environment; such classes can be found in kindergartens, primary schools, middle schools and professional schools. On the other hand, Professional EE aims at cultivating expertise and skills on environmental protection. Students enrolled in higher education and research institutions have the option of choosing related disciplines as their major.

The differentiation of professional and general EE relates to different audiences of EE in China. Firstly, as government officials are gradually aware of the importance of environmental protection, Chinese government realizes that the general public's understanding on this issue plays a major role in protecting and preserving the environment. More importantly, the environmental destruction alongside the rapid economic development has heightened the general public's awareness for EE. Their calls for EE also urge the government to further scale up EE. In other words, media becomes a venue for large-scale and effective EE at the surface level. Therefore, the audience of EE has been expanded from governmental officials to the general public, and the task of EE had been transformed to enhance the environmental awareness of the whole nation. The Ten Countermeasures to Environment and Development issued in 1992 stipulates reinforcing EE, and continuously advancing the environmental awareness. It was until then that EE becomes a form of education to the general public.

\section{EE in China: Future Prospects}

China has implemented EE for 40 years, and it has developed a model of EE with its Chinese characteristics. It emphasizes more on awareness than environmental protection practices and government actions more than efforts of the public. Also, more of a top-down effort than a grass root movement, EE places more emphases on knowledge acquisition than actual practice by individuals. These characteristics prompt some difficulties in the future implementation of EE in China. Section below details some suggestions on ways in which EE 
can be further carried out in China.

\subsection{Emphasizing “awareness" in EE}

The progress of EE in the global arena reveals that the conceptualization of "environment" has been gradually expanded. It is now a holistic concept that relates to ecology, society, economy and politics. Hence, the definition of EE shifts from "education about the environment" to education "for environment and sustainability." It has moved beyond technical and knowledge dimension, and is related to environmental awareness, attitude, values, and ethics. Therefore, in China, such elements should be integrated into the EE curricula.

\subsection{Content of EE}

Specifying the content of EE is important because of the holistic nature of environment as a concept. In fact, curricula of most subject matters are related to the protection and sustainability of the environment. Hence, EE can be seen as a way of education that integrates nature into the curricula. In other words, the content of EE is closely related to its method. As EE promotes "education in the environment," in which participation is important, integrating EE into students and people's daily life becomes a key. Hence, in China, rather than drawing a clear line between knowledge, laws, and ethics about the environment, knowledge, methods and goals of EE are to be integrated together to become a way of life for people.

\subsection{Actors on EE}

EE has long been marginalized in the education sector in China, and was seen as merely affiliated with the task of providing environment protection knowledge. To some extent, this view limited the effectiveness of EE. However, with the issue of The National Action Guidelines for Environmental Communication and Education, EE has been recognized as a primary task for educators in China. After 1992, NGOs aiming at environmental protections are founded in China, and international organizations, such as WWF, have started to implement programs in China. As such, multiple actors are working on expanding EE's scale and diversifying its forms.

\section{Conceptual Difficulties of EE}

Firstly, EE and ESD in China are oftentimes viewed as forms of environmental protection, which refers to the treatment and reuse of waste gas, waste water and solid waste. However, the meaning behind EE and ESD are drastically different. What does ESD refer to, such as human sustainability, social sustainability, economic (financial) sustainability, or natural (environmental) sustainability (Kopnina, \& Meijers, 2014)? Another example: Do environmental science, environmental engineering, environmental management, etc. belong to EE or ESD? Should we set up a major for SD or ESD? Basically, the clarification of these confusions depends on how to understand the relationship between human, society and the environment.

Secondly, teachers have low-level of motivation to incorporate EE in their teachings. Study 
pointed out that only a small number of teachers stated they do "a lot of EE" in class (The BNU-Gakugei Research Group, 2002). They list the following major reasons that impede the implementation EE lack of time, lack of teaching materials, lack of recognition from the head of school, lack of finance, and difficulties with the implementation. According to the Research Group, EE is taught as a combination of book-knowledge and out-of-classroom-activities, such as tree planting activities, cleaning up public spaces and collecting used batteries.

Thirdly, the lack of environmental awareness of the general public and school personnel impeded the implementation of EE and ESD. A study stated that school age children' environmental awareness decline as the income of their parents increase (Wang, 1998). Since 1998, the overall level of public environmental awareness in China had been improved and the development process had a characteristic that is similar to "Environmental Kuznets Curve" (Note 1). It's predicted that the overall level of public environmental awareness in China will increasingly accelerate in the future. However, those living in rural areas and those receiving lower education should be the key groups to receive education on environmental cognition (Yan, Kang, Xie, et al., 2010). Therefore, further cultivating interests and awareness of EE and ESD is pivotal in fostering environment protection in China.

Last but not the least, contradiction between economic growth and environmental protection and sustainable development becomes more and more apparent. Currently, China is still facing the two inevitable tasks: developing the economy and improving people's lives. How to deal with the contradiction depends on the governmental attitude and attention. In China, all levels of governments, from the central government to local level governments, play important roles in every field of the society. Therefore, it is very important to gain governmental support. Influenced by the traditional notion of development, the government has mostly focused on economic growth (GDP). Ways in which Chinese government balances between economic growth and sustainable development remains to be seen.

\section{Going forward: Some Recommendations}

(1) The fundamental framework of EE should gear toward providing adequate awareness, knowledge, attitude, skills, evaluation ability, and participation for EE and ESD in China. Meanwhile, findings from academic research should also be put into practices, with the consideration of the current situation of political, economic and cultural contexts in China. In future research, the research subjects should be expanded to the cultural and social dimensions, such as environmental justice and equality, social participation in environmental protection and the promotion of SD in society; both quantitative and humanistic-oriented qualitative research method should be strengthened; financial support for such research should be ensured (also see Tian, Yun, \& Yin, 2007).

(2) Policies of EE need to be enacted and implemented, so as to reflect the diverse needs based on developing economic growth and cultural situations across the country. China's environmental policies have evolved and deepened: (a) status from national basic policy to sustainable development strategy, (b) focus changed from pollution control to combination of pollution control and ecological protection, (c) method changed from end control to source 
control, (d) scope changed form point treatment to watershed and territory treatment, and (e) management style changed from using executive power to using legal and economic measures (Zhang, Wen, \& Peng, 2007). The understanding of environmental policy will help make policies of EE and ESD. Currently, policies of EE in China have touched on basic education, higher education, in-service education, and public education (Meng, \& Wei, 2003). These policies need to be further expanded to provide professional programs, such as effective communication, professional training, according to the different development levels in different areas of China.

(3) It is imperative to accelerate the legislation process of environmental education law. The major aspects of environmental education law should be learned from the Unite States, Brazil, Japan, South Korea, Philippine, Taiwan and other countries and regions. Environmental education law should set up detailed rules such as certification criteria, effective budget (fund) plan, penalty rule as soon as possible (also see Wang, Zhu, \& Shen, 2013; Qi, 2014). Moreover, implementation of EE should also inform and shape existing environment protection law as well.

(4) Government, regions, and environmental NGOs should foster and strengthen its bilateral or multilateral international exchanges and cooperation. This includes participating in SD policy-making, promoting the concept of SD, engaging in SD cooperation projects, improving the SD capacities. On the basis of learning from the western EE and ESD modes, China should develop its own cultural model of EE and ESD. Integrating the Confucian philosophical tradition and key values such as harmony, sustainable relationships with nature, and trans-generational communication and support becomes pivotal in this task (Lin, \& Ross, 2005).

EE in China has made considerable progress since 1973. In particular, during the period of United Nations Decade of Education for Sustainable Development (UNDESD), China had accomplished three major shifts: from an international concept of ESD to a Chinese concept, from intervention and action research to public policy-making, and from school-based innovation to school-community partnership-building ( $\mathrm{Du}, 2008)$. However, to combat the deepening environmental degradation and deconstruction, Chinese government and citizens, as well as NGOs, must concertedly work together to further strengthen and foster EE in China.

\section{Acknowledgements}

The research is funded by the China Scholarship Council. No. 201306775029. Thanks for Prof. Jing Lin, University of Maryland.

\section{References}

Chen, L., \& Sun, D. (2009). Theory and Practice of Education for Ecological Civilization in China. Beijing: Central Compilation and Translation Press.

Chinese Society for Environmental Sciences (CSES). (2008). The History of Chinese Society for Environmental Sciences. Shanghai: Shanghai Jiaotong University Press. 
Cui, J. (2009). New Opinions on Citizen's Environmental Education. Ji'nan: Shandong University Press.

Du, Y. (2008). A Decade Review on ESD in China. Journal on Education for Sustainable Development in China, 1, 1-2.

Gough, A. (2005). Sustainable Schools: Renovating Educational Processes. Applied Environmental Education and Communication, 4(4), 339-351. http://dx.doi.org/10.1080/15330150500302205.

Huang, Y. (2003). Development and Trend of Environmental Education in China. Environmental Education, 2, 8-16 (in Chinese).

Kopnina, H., \& Meijers, F. (2014). Education for Sustainable Development (ESD): Exploring Theoretical and Practical Challenges. International Journal of Sustainability in Higher Education, 15(2), 188-207. http://dx.doi.org/10.1108/IJSHE-07-2012-0059.

Lin, J., \& Ross, H. (2005). Addressing Urgent Needs: The Emergence of Environmental Education in China. Woodrow Wilson Environmental Series, 7, 74-78.

Meng, Q., \& Wei, Z. (2003). The Need for the Development of Environmental Education Policy and Study on the Basic System of China's Environmental Education Policy. Journal of Inner Mongolia Normal University (Educational Science), 16(5), 20-22 (in Chinese).

Qi, H. (2014). Status of Environmental Education Legislation and Reflection of Chinese Environmental Education Legislation. World Environment, 4, 74-76 (in Chinese).

Sohn, L. B. (1973). The Stockholm Declaration on the Human Environment. The Harvard International Law Journal, 14(3), 423-515.

The BNU-Gakugei Research Group. (2002). Environmental Education System toward a Sustainable Society in Japan and China. A Joint Research Undertaking of Beijing Normal University, China and the Department of Pedagogies of Tokyo Gakugei University, Japan 1999-2001. Beijing, Tokyo.

Tian, Q. (2001). An Introduction to Environmental Education in Primary and Secondary Schools. Beijing: Huaxia Publishing House.

Tian, Q. (2008). Chinese ESD Policy Research. In M. Y. Choi (Ed.), ESD Policy and Implementation in China, Japan and Republic of Korea (pp. 79-110). Hayama: Institute for Global Environmental Strategies.

Tian, Q., Yun, Y., \& Yin, P. (2007). The History and Trend of Environmental Education Research in China. China Population, Resources and Environment, 17(1), 130-134 (in Chinese).

UNESCO-EPD. (1997). Declaration of Thessaloniki (UNESCO Publication No EPD-97/CONF.401/CLD.2). Paris: Author. 


\section{Macrothink}

UNESCO-UNEP. (1978). The Tbilisi Declaration. Connect: UNESCO-UNEP Environmental Education Newsletter, 3(1), 1-8.

United Nations Department of Economic and Social Affairs (UN DESA, 1992). Agenda 21. Retrieved 26th January, 2015 from http://www.un.org/esa/sustdev/agenda21.htm.

Wang, M., Zhu, Z., \& Shen, H. (2013). International Comparisons of Concepts in Environmental Education Law and Practice of Environmental Education Legislation in China. World Environment, 5, 21-22 (in Chinese).

Yan, G., Kang, J., Xie, X., et al. (2010). Change Trend of Public Environmental Awareness in China. China Population, Resources and Environment, 20(10), 55-60 (in Chinese).

Yen, N. (1993). Education is the Basis of Environmental Protection. Environmental Science, 4, 5-7 (in Chinese).

Yu, K. (2005). Notion of Scientific Development and Ecological Civilization. Marxism \& Reality, 4, 4-5 (in Chinese).

Zhang, K., Wen, Z., \& Peng, L. (2007). Environmental Policies in China: Evolvement, Features and Evaluation. China Population, Resources and Environment, 17(2), 1-7. http://dx.doi.org/10.1016/S1872-583X(07)60006-0.

Note 1. The Environmental Kuznets Curve (EKC) hypothesizes that the relationship between per capita income and the use of natural resources and/or the emission of wastes has an inverted U-shape. According to this specification, at relatively low levels of income the use of natural resources and/or the emission of wastes increase with income. Beyond some turning point, the use of the natural resources and/or the emission of wastes decline with income.

\section{Copyright Disclaimer}

Copyright reserved by the author(s).

This article is an open-access article distributed under the terms and conditions of the Creative Commons Attribution license (http://creativecommons.org/licenses/by/3.0/). 